\title{
Reexame da noção de hierarquia temática
}

\author{
Carlos Franchi \\ Unicamp/USP \\ Márcia Cançado \\ Universidade Federal de Minas Gerais
}

$\mathrm{E}$

xiste uma intuição, datada de muito tempo dentro das teorias lingüísticas, que a relação entre a sintaxe e os papéis semânticos é altamente restringida por princípios universais. Um desses princípios, mais recente e talvez o mais forte, é o de BAKER (1988): a hipótese da "Uniformity of Theta Assignment Hypothesis" (UTAH). A UTAH afirma que relações temáticas idênticas entre itens são representadas por relações estruturais idênticas entre esses itens no nível da estrutura profunda. Uma noção paralela a essa é a da "Universal Alignment Hypothesis" (ROSEN, 1984; PERMULTER e POSTAL, 1984), gerada dentro do quadro da Gramática Relacional. Uma versão anterior é a da Gramática de Casos de FILLMORE (1968), que expressa basicamente a mesma idéia: todo papel semântico é mapeado em um único "caso sintático profundo". 
Sabe-se, porém, que as relações gramaticais superficiais não obedecem a tão estrita correspondência. A conseqüência é que hipóteses teóricas tão fortes e rígidas levam a um custoso mecanismo de transformações de movimento, de apagamento e inserção, e de inserção de preposições, a fim de conseguir-se uma passagem da estrutura$\mathrm{P}$ para a estrutura-S. Outras hipóteses menos restritivas também apareceram na literatura. ${ }^{1}$

\section{ALGUMAS OBSERVAÇÕES E INTUIÇÕES PRELIMINARES}

Ao invés de atribuir um papel temático a cada posição sintática particular, essas teorias invocam um mapeamento entre uma lista ordenada de papéis temáticos (a "Hierarquia Temática") e uma lista ordenada de papéis sintáticos.

Não há, porém, inteiro consenso sobre como implementar essa hipótese. As propostas divergem já na questão da motivação de uma hierarquia temática. De um modo geral, os autores a definem como parte da própria organização semântico-conceitual seja da estrutura do evento, seja da representação lexical. Nesse sentido vão os autores que temos citado. Convém, entretanto, lembrar que, no funcionalismo, a hierarquia temática é determinada por princípios relativos a noções como as de topicalidade (GIVÓN, 1984), ou a noções como as de ponto de vista e fluxo de informação (DELANCEY, 1984; CAMACHO, 1994). Embora, como já observamos, diferentes estruturações sintáticas da descrição de um evento de fato expressem diferentes pontos de vista (refletindo decisões pragmáticas no nível do discurso), as condições de possibilidade dessas diferentes perspectivas é que estão fortemente restritas pelo léxico e pela morfologia - em última análise pela gramática de uma língua. Como parte das "regras de correspondência" entre estrutura semântica e sintática, o princípio deve, pois, ser definido independentemente.

As propostas diferem, ainda, em como as regras de correspondência são especificadas. MARANTZ (1984) e FOLEY e VALIN (1984) mapeiam as relações semânticas diretamente dentro de configurações 
sintáticas (estruturas frasais); BRESNAN e KANERVA (1989) as mapeiam, em sua Lexical Functional Grammar, sobre as funções gramaticais SUBJ and OBJ; CARRIER-DUNCAN (1985) as mapeia sobre seqüências de marcadores de caso NOM e ACC (em seu estudo sobre o Tagalog); GRIMSHAW (1990) mapeia a estrutura argumental hierárquica sobre uma estrutura argumental sintática; JACKENDOFF (1990) elabora um processo de ligação entre a estrutura conceitual lexical e a sintaxe. Para todas as abordagens, a concepção básica do sistema é a mesma, variando a escolha das noções sintáticas em jogo - categoriais, funcionais, certas configurações estruturais.

Finalmente, do ponto de vista da ordenação dos papéis temáticos em uma hierarquia, apesar de pressuposta, geralmente, como universal, existem controvérsias quanto à posição relativa de alguns papéis, como os de Tema, Instrumento, Meta/Fonte/Locativo e também quanto à relação dos papéis dentro desse último grupo. Isso decorre, como observamos no texto anterior, de que, na definição da hierarquia temática, não se faz distinção entre funções e macro-funções, nem entre os "tiers" ou planos em que se organizam, tentando-se estabelecêla em uma única seqüência linear. Um exemplo disso é a hierarquia proposta por BRESNAN e KANERVA (1989):

(1) Agente $>$ Beneficiário $>$ Experienciador $>$ Instrumento $>$ Tema/Paciente $>$ Locativo.

Essa formulação, por privilegiar o critério de escolha do elemento para a "promoção a sujeito", dificulta muito o estabelecimento correto das correspondências entre as funções semânticas e as funções gramaticais, sobretudo no que diz respeito à organização da estrutura dos argumentos internos. Já vimos antes alguns problemas para a formulação dessa hierarquia causados pela identificação de Paciente, Resultativo e Objetivo a Tema e de caracterizar-se o Tema como o objeto locado (estativo) e movido (afetado). Com essas breves referências às propostas correntes sobre o princípio da hierarquia temática, passamos a reexaminá-la dentro do quadro teórico em que temos trabalhado, restringindo, porém, nossa discussão às relações gramaticais básicas da oração. As linhas gerais da reelaboração que fazemos são: 
- o princípio da hierarquia temática preside à organização da diátese dos predicadores (de sua representação lexical) e à distribuição dos argumentos nas posições da estrutura categorial-sintática das orações;

- a hierarquia temática tem um caráter implicacional no sentido de que ela pressupõe uma determinação de uma sucessiva construção das relações temáticas na dependência de outras conforme a eventualidade descrita;

- disso decorre que a hierarquia temática não é definida em um único plano (em uma única seqüência linear), mas em uma estrutura pluridimensional complexa sob diferentes critérios convergentes: a diátese do predicador, o "tier" (da causação ou ou da locação) em que o papel temático se define, a propriedade semântica que o caracteriza em uma macro-função ou função específica;

- processos componenciais estão em jogo: além da diátese das propriedades temáticas inscritas na representação dos itens lexicais predicadores, efeitos composicionais resultantes do sentido de seus argumentos ou adjuntos podem abrir outras possibilidades de instanciação sintática.

1.1. A motivação mais geral para uma Hierarquia Temática é a de expressar as generalizações sobre a ordenação dos argumentos na estrutura argumental sintática de um predicador. Em outros termos, estabelecer a correlação entre as relações temáticas e as relações gramaticais (MARANTZ, 1984). Nas propostas lineares, os argumentos mais profundos na hierarquia se combinam sintática e semanticamente com o predicador antes do que os argumentos correspondentes a papéis mais altos (BRESNAN e KANERVA, 1989). Marantz observa que os argumentos de um predicador têm diferentes graus de relevância para a caracterização do evento descrito, e chama a atenção para a assimetria, desse ponto de vista, das posições de sujeito (especificador) e complemento. 
As Predicações e relações temáticas por elas determinadas possuem um estatuto teórico no plano da representação semântica. Dado o seu caráter funcional, não se há de falar, portanto, neste quadro teórico, de "atribuição de papéis temáticos" na estrutura sintática, como um processo de "atribuição de traços". A questão relevante é:

- como se explicitam essas relações na sintaxe? ou como os papéis temáticos se tornam visíveis, na representação sintática, para a interpretação?

A resposta da teoria de Princípios e Parâmetros ("Predicação", 1.3) é elaborar uma teoria sintática dos Casos Abstratos como contraparte da teoria dos Papéis Temáticos. ${ }^{2}$ Aqui, porém, não faz sentido falarse de "marcação- $\Theta$ " na sintaxe: o princípio da transparência nos impõe somente que as representações sejam tais que se possa expressar do modo mais direto e simples possível a correlação sentido-estrutura sintática e esse é o propósito do Princípio da Hierarquia Temática. Neste ponto, basta-nos a observação descritiva de que, no Português, há basicamente três mecanismos sintáticos de "visibilidade" dos papéis temáticos: ${ }^{3}$

- o caso de visibilidade do argumento (A-visibility) na posição estruturalmente definida do complemento verbal e preposicional, via regência e adjacência;

- a visibilidade via "cópia" de traços do argumento no núcleo do predicador (H-visibility), nos casos de concordância verbal e adjetival;

- a visibilidade pela mediação das preposições, nos casos em que, não sendo disponíveis os processos acima, o predicador ainda possui em sua diátese um papel temático a ser saturado e no caso das adjunções.

Isso nos deixa com três posições sintáticas a considerar no estabelecimento da correspondência entre funções semânticas e funções gramaticais que, por enquanto, serão referidas simplesmente como "sujeito", "complemento do predicador", "complemento da 
preposição". As duas primeiras constituem uma configuração nuclear; os argumentos que se manifestam nos sintagmas preposicionados, uma configuração periférica.

1.2. Convém discutir previamente como se representam as propriedades temáticas dos predicadores para melhor formular o princípio da Hierarquia Temática. Lembre-se de que a teoria generalizada dos papéis temáticos pressupõe que eles se definam para qualquer relação semântica que se estabeleça com um predicador, independentemente da relação sintática que a expresse (predicação, complementação, adjunção) e da categoria gramatical em que o predicador se manifeste. Considere-se, ainda, que a noção de papel temático não está restrita à projeção de propriedades de um item lexical, dado que se assumem as conseqüências semânticas da composição de um predicador lexical com seus complementos e adjuntos. Uma oração como:

(2) Maria [[[ quebrou o vaso ] por descuido ] no clube ]

determina para os argumentos Maria e vaso um conjunto de relações relevantes para a interpretação semântica:

(3) a - Maria controla sua ação (mesmo que intencionalmente não desejasse o resultado de sua ação),

b - Maria foi descuidada (ao quebrar o vaso),

c - O evento descrito ocorreu no clube > Maria estava no clube,

(3) d - O vaso foi afetado pelo processo desencadeado por Maria > o vaso passou de um estado a outro,

de que se derivam diretamente (nas predicações primárias) e composicionalmente (nas predicações secundárias) diferentes papéis temáticos: Maria é Agente relativamente ao predicador quebrou por descuido o vaso no clube; é Experienciador na predicação secundária com o adverbial por descuido que se compõe à predicação verbal; e objeto locado na predicação secundária com o adverbial no clube. Vaso é o objeto afetado no processo. 
Evidentemente, não se pode falar que todas essas relações constituem acarretamentos lexicais do verbo quebrar. Primeiro, notese que a agentividade de Maria resulta do predicador complexo e não de um acarretamento lexical de quebrar.

(4) a - Com o vento forte, o vaso caiu e quebrou,

b - Foi a queda no chão que quebrou o vaso;

(5) a - Só foi possível quebrar essa noz com uma marreta,

b - Só essa marreta vai quebrar essa noz.

Assim, para satisfazer o critério- $\Theta$, significado, basta a ocorrência de um argumento em um dos papéis temáticos da macro-função CAUSA (Agente, Força, Causa, Instrumento).

Compare-se esse verbo a outros como assassinar, escrever, olhar, admitir, etc., a que WHITAKER-FRANCHI (1989) chamou de "tipicamente agentivos", por acarretarem a agentividade de seu argumento-sujeito:

(6) a - Maria assassinou o companheiro,

b - Maria escreveu um artigo para a Veja,

c - Maria olhou de soslaio o adversário,

d - Maria admitiu sua culpa no incidente.

Ou seja, Maria se associa a um papel Agente pela própria diátese verbal.

Por força do modo pelo qual se caracterizaram, na teoria, as relações e papéis temáticos, para propor uma representação lexical consistente com esses fenômenos, devemos cuidadosamente avaliar se as propriedades associadas a essas relações e funções decorrem de acarretamento estritamente lexical. Conseqüentemente, devemos propor distintas representações semânticas para quebrare assassinar. Informalmente: 
(7) QUEBRAR: V, \{ CAUSA, Paciente $\}$

ASSASSINAR: V, \{ Agente, Paciente \}

Alguns poderiam objetar que o Locativo (ou Temporal) deveria estar incluído na rede temática: toda descrição de um evento pressupõe que ele ocorra em dimensão espaço-temporal, em um certo tempo e lugar. Poderíamos acrescentar, ainda, que toda descrição de um evento pressupõe que ele ocorra por uma causa qualquer. Essa é, porém, justamente a razão para não incluir as etiquetas de Tempo, Lugar, Causa na representação lexical dos verbos: um traço categorial ou funcional que se associa indiferentemente a todos os predicadores não os distingue em nada para os efeitos de generalizações teóricas. ${ }^{4}$

Não se quer dizer que Tempo, Lugar, Causa não sejam "selecionados" por certos predicadores como parte de sua diátese específica. Lugar/Tempo fazem parte da diátese de preposições como em, sobre, durante ou de verbos como começar, acabar, durar, estar.

(8) a - Sam vai começar a prova em dez minutos,

b - Sam começou a cerca neste pé de eucalipto;

(9) a - A prova de redação durou duas horas e, agora, está no fim,

b - Os alunos fizeram a prova durante duas horas .

Justifica-se, pois, a representação lexical desses predicadores:

(10) a - COMEÇAR: V, \{CAUSA, Locado, Locativo\}

b - DURANTE: P, \{Locado, Locativo\}

Essas representações ${ }^{5}$ nos permitem distinguir diferentes classes de predicadores, associadas a diferentes propriedades sintáticas, possibilitando-nos, inclusive, estabelecer generalizações descritivas a partir delas. Lembrem-se, por exemplo, as restrições que se impõem sobre a classe de verbos que entram em construções ergativas, a que já nos referimos de passagem: a de que devem ter como complemento um OBJETO AFETADO e não podem ter sequer implícita uma relação agentiva. Essas construções estão, portanto, 
minimamente restritas à classe de verbos do tipo quebrar, cuja diátese se representa com as macro-funções CAUSA e OBJETO AFETADO. ${ }^{6}$

A maior flexibilidade na caracterização dos papéis temáticos nos permite estabelecer relações entre verbos correlatos em sua representação lexical. Podemos, por exemplo, considerar nessa representação os diferentes "tiers" em que os papéis temáticos se organizam. Retomemos um exemplo utilizado em textos anteriores:

(11) a - Sam alugou/emprestou um carro para Maria,

b - Maria alugou/emprestou um carro de Sam.

Para explicar essas instanciações sintáticas representamos alugare emprestar com papéis temáticos do "tier" da ação e da locação:

(12) AlUGAR: V, \{ Agente-Fonte, Agente-Meta, Objetivo, Valor \}, deixando-se a "escolha" da perspectiva dependente de regras de seleção do sujeito-Agente definidas na Hierarquia Temática (bem como a seleção das preposições apropriadas).

Note-se que nem sempre será possível evitar, na representação, uma explícita indicação da perspectiva em que se constrói a diátese do predicador. Vendere comprar, por exemplo, também se representam com as mesmas etiquetas temáticas; cada verbo, porém, expressa somente uma perspectiva em que se toma o evento, pelo que se deve indicá-la, em cada caso. Informalmente, adotemos o diacrítico* (como sugeriu MARANTZ, 1984):

(13) VENDER: V, \{ ${ }^{*}$ Agente-Fonte, Agente-Meta, Objetivo, Valor \} COMPRAR: V \{ Agente-Fonte, "Agente-Meta, Objetivo, Valor \}.

Deve-se entender que a notação dos papéis temáticos na forma de um simples conjunto de etiquetas funcionais temáticas não decorre de um não-comprometimento com a existência de um sistema estruturado de papéis temáticos como é o caso de Marantz. O que estamos propondo é que a representação lexical pode dispensar-se de uma direta indicação das posições sintáticas (nucleares e periféricas), como 
nas notações habituais (por exemplo, ZUBIZARRETA, RAPPAPORT e LEVIN (1988), ZUBIZARRETA (1987), HIGGINBOTHAM (1985), entre outros), porque essa estruturação deve resultar da aplicação do princípio da Hierarquia Temática.

Seja, porém, qual for a notação que se adote nessas representações, o importante é notar que os papéis-temáticos que caracterizam a diátese de um predicador não esgotam as relações semânticas de uma oração, constituindo somente uma fonte primeira de restrições: a representação se limita às macro-funções e funções temáticas acarretadas lexicalmente pelo definidos, seguindo Dowty, pelo item lexical predicador.

Essas breves indicações bastam a nossos propósitos.

\section{HIERARQUIA TEMÁTICA}

Nas representações lexicais da diátese do predicador, sugeridas no item anterior, se expressa em geral, sua adicidade, sobre o que todos concordam, e a qualidade temática de seus argumentos. Para fixar a Hierarquia Temática examinaremos, no primeiro subitem, algumas classes mais comuns de verbos em Português. Consideraremos a "diátese plena" desses verbos, ou seja, aquela que aparece em contextos/situações em que se descreve o evento com o maior número de "participantes". Embora o princípio da hierarquia temática se estenda naturalmente a quaisquer predicadores (verbais, adjetivais, preposicionais simples ou complexos), limitaremos ilustrativamente a análise, neste texto, à predicação verbal.

Em um segundo subitem, discutiremos os aspectos relevantes de promoção argumental para, enfim, propor os esquemas em que se baseia o princípio da hierarquia temática.

2.1. Examinemos algumas classes de verbo particularmente em relação a seu argumento nuclear sujeito (especificador).

2.1.1. A grande maioria dos verbos do Português se inclui na classe que se constuma chamar de "ação-processo" e de "atividade", ou seja, os que admitem ou pressupõem traços de agentividade de um 
de seus argumentos, como quebrar e assassinar acima; como é consensual, esse argumento se realiza na posição sintática de "sujeito" (especificador). ${ }^{7} \mathrm{Na}$ posição de "complemento", porém, se realiza uma diversidade de papéis temáticos:

(14) a - \{ Agente, Paciente $\}$ :

Sam assassinou o parceiro,

b - \{ Agente, Beneficiário, ... \}: Sam ajudou Maria (a vestir-se), c - $\{$ Agente, Experienc., ... $\}$ : Sam assustou Maria (com o grito),

(14) $d-\{$ Agente, Instrumento $\}:$ Sam usou uma faca,

e - $\{$ Agente, Objetivo $\}$ :

Sam observava a paisagem,

$\mathrm{f}-\{$ Agente, Resultativo $\}: \quad$ Sam construiu uma casa,

g - $\{$ Agente, Obj. movido, ... $\}$ : Sam levou o livro,

Entretanto, já vimos que um grande número desses verbos admite na posição de sujeito outros papéis temáticos da macrofunção CAUSA, e mesmo a interpretação puramente causal de um argumento-sujeito animado:

(15) a - Esses alunos ainda me matam,

b - O descuido do médico matou a criança,

c - A leitura do livro ajudou Maria,

d - Esse novo manual ajudou Maria,

e - O grito de Sam assustou Maria,

f - O medo da morte levou Sam ao psiquiatra.

A hipótese, pois, a ser considerada é a de que a macro-função CAUSA deve ser proeminente na hierarquia, em relação aos múltiplos papéis temáticos que os verbos transitivo-ativos associam ao argumento que tomam como complemento ou se expressam perifericamente em sintagmas preposicionados: CAUSA > ... . . . Isso explicaria a seleção do argumento para a posição de sujeito nas classes de verbo: 
(16) $\mathrm{V}:\{$ CAUSA, ... $\}$,

$\mathrm{V}:\{$ Agente/Causa/Instrumento, ... $\} .^{8}$

São, porém, raros os verbos que selecionam Causa e Instrumento (com exclusão do Agente). Tipicamente causativos são os verbos da classe preocupar, cujas propriedades foram estudadas cuidadosamente por CANÇADO, 1995. JACKENDOFF (citando BRESNAN e GRIMSHAW) aponta como instrumental um verbo como servir.

(17) a - A proximidade da prova encanta Maria,

b - Essa faca/Sam somente serve para descascar batatas.

2.1.2. Excluindo os verbos "de ação", examinemos alguns verbos experienciais e benefactivos, ou seja, que tomam, na posição de sujeito, um Beneficiário ou um Experienciador. Desde logo se observa que, se tal ocorre, fica excluída a presença de um OBJETO AFETADO (Paciente) no "tier" da causação (e mesmo um Resultativo), visto que Beneficiário e Experienciador, embora compatíveis com traços de agentividade, não incluem entre as propriedades que os caracterizam a causalidade direta de um processo:

(17) \{Beneficiário, Objetivo/Movido, Fonte \}:

a - Sam recebeu o livro (de Maria),

b - Sam tomou emprestado um livro da biblioteca;

(18) \{Beneficiário, Valor, Causa/Fonte \}:

Sam lucrou mil reais (com a venda dos livros/dessa venda de livros),

(19) $\{$ Experienciador, Objetivo $\}$ : Sam teme/olha Maria,

Observe-se, porém, que alguns dos raros verbos estativos possuem em sua diátese os papéis temáticos Beneficiário/Experienciador e Objetivo, ${ }^{9}$ com proeminência, na posição de sujeito, do argumento associado a este segundo papel: 
(20) a - Este livro não convém aos alunos/ não lhes convém,

b - A aprovação do projeto interessa a todos/ lhes interessa,

c - Este livro custou cem reais aos alunos;

(21) a - Este livro não agrada a ninguém/ não lhe agrada,

b - A aprovação do projeto lembra um caso semelhante ao deputado/lembra-lhe um caso semelhante.

Estes exemplos nos mostram que a proeminência atribuída de um modo consensual ao Beneficiário e ao Experienciador na hierarquia temática (Jackendoff, Grimshaw, Bresnan, entre outros) precisa ser modificada. Façamos aqui um parêntese.

Vimos antes que essas duas etiquetas temáticas não expressam um único papel temático-tipo, no sentido que atribuímos a essa noção, via definição de Dowty. A realização de um Beneficiário na posição de sujeito pode compor o traço com que a literatura tem caracterizado esse papel temático (interesse no resultado do processo, elemento a que se destina o resultado do processo) com traços de agentividade (iniciativa, intencionalidade e, sobretudo, um controle [in]direto do processo). Assim, o Beneficiário, enquanto um Agente-Meta, concorre mesmo, em muitos casos, com um Agente-Fonte diretamente responsável pelo processo. Observe-se que são justamente esses traços de agentividade que contrapõem (17)-(18) a (20).

Por outro lado, observamos também que "Experienciador" é uma etiqueta cômoda para distinguir diferentes papéis temáticos que podem incluir propriedades distintas características de ação, afetação ou estado (ver, por exemplo, CHAFE, 1970; COOK, 1979). A análise de CANÇADO (1955) dos psico-verbos mostra o contraste entre:

(22) a - Maria teme Sam,

b - Maria preocupa Sam,

c - Maria assustou Sam;

(23) a - ? Maria parou de temer Sam,

b - ??? Maria parou de preocupar Sam lambas no sentido ativo relevantel;

c - Maria parou de assustar Sam 
Mais claramente, o controle do processo pelo Experienciador-sujeito (embora seja difícil falar-se em "ter um papel no desenvolvimento do processo") distingue (a) de (b):

(24) a - Sam é temido/foi assustado por Maria,

b - *Sam foi preocupado por Maria,

Nessa linha, consideramos antes, ao fazer comentários sobre esse "papel temático", que os raros verbos com "Experienciador" na posição do sujeito como olharpara, acarretam a propriedade de esse argumento "ter o controle do processo" propriedade associada ao Agente prototípico; outros da classe de "temer/sofrer" são estativos ou processuais, embora o Experienciador mantenha o controle do estado ou processo ; outros, ainda, como o complemento-Experienciador de verbos da classe "assustar", são Objetos Afetados.

Usar, portanto, esses papéis temáticos (assim como Fonte, Meta, Tema) em uma mesma seqüência linear de etiquetas em uma hierarquia temática é uma fonte de ambigüidades e de inconsistências. A idéia é considerar, em cada caso em que nos referimos a esses papéis, as propriedades realmente relevantes (agentividade, afetação, estatividade) lhes são acarretadas pelos predicadores.

2.1.3. Consideremos agora outros predicadores verbais. Os "de processo" são, em geral, verbos intransitivo-ergativos que tomam como argumento-sujeito um argumento da macro-função OBJETO AFETADO:

(25) a - $\{$ Paciente $\}: \quad$ O parceiro de Sam morreu, Sam escorregou,

b - $\{$ Experienciador $\}$ : O parceiro de Sam não sofreu,

c $-\{$ Movido, ... $\}$ Sam rolou (pela escada),

O livro caiu (da mesa),

A encomenda chegou (em casa).

Alguns poucos predicadores admitem um complemento que é, porém, sempre um papel temático estativo - Resultativo ou Objetivo (Termo de referência, Valor): 
(26) a - João tornou-se/ficou o líder de todo o grupo,

b - João, pouco a pouco, igualou o irmão na esperteza,

c - Alcançar esse objetivo valeu/custou um grande sacrifício.

No caso de verbos de estados, alguns transitivos, o sujeito é sempre o Objeto Estativo (ou simplesmente, Objetivo) de um predicador atributivo ou Objeto Movido, de um predicador no "tier" da locação:

(26) a - $\{$ Objetivo $\}$ :

Sam é brasileiro,

b - \{Objetivo, Valor $\}:$ O livro custou cem reais aos alunos, Sam não vale esse sacrifício,

c - \{Objetivo, Termo de Referência \}: O seu ordenado equivale ao meu,

d - \{ Locado, Locativo $\}$ Sam mora em São Paulo perto dos sogros, Sam está em casa.

Em todos esses exemplos, se excluem da diátese do predicador papéis temáticos Agente (ou com traços de agentividade) e Objeto Afetado. Não encontramos qualquer predicador que tomasse como argumento sujeito papéis temáticos da macro-função DESTINAÇÃO.

A hipótese a que esses dados nos levam é a de que, relativamente à posição sujeito, a hierarquia temática deve construir-se, até aqui, como:

\section{(27) CAUSA $>$ OBJETO AFETADO $>$ ESTATIVO $>(\text { DESTINAÇÃO })^{10}$}

2.2. Se na rede temática existe um argumento da macro-função CAUSA, independentemente do papel específico que a realiza, o complemento é sempre o OBJETO AFETADO, se este compõe a diátese do predicador: o Paciente, o Experienciador (quando afetado, ou seja, quando o predicador acarreta uma "mudança de um estado psicológico a outro", o Objeto Movido (implicando uma mudança de locação) e o Beneficiário (quando, além de interessado no processo, é afetado por ele): 
(28) Paciente: a - Sam assassinou o parceiro,

b - Esses alunos ainda me matam,

c - Sam quebrou o vaso de barro,

d - O descuido de Sam quebrou o vaso de barro,

e - Esse martelo não vai quebrar as nozes;

(29) Experienciador: a - Sam assustou Maria (com o grito),

b - O grito de Sam assustou Maria,

c - Esse filme encantou Maria;

(30) Objeto Movido: a - Sam levou o livro (na escola),

b - O caminhão transportou os móveis para São Paulo,

c - O medo da morte levou Sam ao psiquiatra;

(31) Beneficiário: a - Sam ajudou Maria (a vestir-se),

b - O descuido com a higiene prejudicou Maria;

Há, entretanto, verbos (inclusive de ação ou atividade) cuja diátese não inclui um OBJETO AFETADO. São verbos basicamente de três tipos. O primeiro toma como argumento, na posição de complemento, um Objetivo, ou seja um elemento com que a ação está relacionada em vários sentidos, sem que, entretanto, seja afetado por essa ação em seu estado:

(32) Objetivo: a - Sam escolher o livro de Chomsky para ler,

b- Sam criticou esse livro depois,

c - Sam leu o livro com cuidado;

(33) Destinação: a - João visa (a) propósitos muito claros,

b - Estas medidas objetivam um resultado consensual. 
Um segundo tipo inclui os verbos acima apontados que tomam Beneficiário e Experienciador como sujeitos:

(33) a - Sam recebeu o livro,

b - Sam comprou o livro;

(34) a - Sam observava a paisagem,

b - Sam conhece bem a teoria chomskyana,

c - Sam teme Maria;

Um terceiro tipo inclui os verbos que tomam um Resultativo:

(35) a - Sam construiu uma casa nova,

b - Sam escreveu um poema.

Finalmente, um conjunto de verbos, em geral estativos, na ausência de um papel temático OBJETO AFETADO (Paciente, Experienciador, Objeto Movido) ou Objetivo, tomam como argumento, na posição de complemento, um argumento de um outro papel, que supomos mais baixo na hierarquia em relação ao seu sujeito:

(36) a - \{ Agente, Instrumento \}: Sam usou uma faca,

b - \{ Beneficiário, Valor, ... $\}$ : Sam lucrou mil reais na venda,

c - $\{$ Objetivo, Valor $\}$ : O livro custou cem reais aos alunos, Sam não vale esse sacrificio,

d - \{Objetivo, T. de Refer.\}: O seu ordenado iguala o meu, e - \{Locado, Locativo \}: Sam habita esta casa.

Dessa exemplificação se vê que, na posição de complemento, se engendram os argumentos associados a papéis temáticos da macro-função OBJETO AFETADO; na ausência deste na diátese do predicador, o argumento ESTATIVO. No caso dos complementos Beneficiário e Experienciador, valem as mesmas observações feitas a propósito da posição de sujeito. Em síntese, a realização argumental da posição de complemento obedece à mesma hierarquia temática proposta em (27). Um terceiro papel temático na diátese de um 
predicador ou as relações semânticas construídas mediante adjunção ocupam as posições sintáticas periféricas, construindo-se como sintagmas preposicionados. Alguns exemplos com sintagmas preposicionados poderiam pôr em dúvida a proeminência de CAUSA (construído como um sintagma preposicionado) em relação ao OBJETO AFETADO e ao ESTATIVO quando se trata de verbos de processo e de estado:

(37) a - O parceiro de Sam morreu de doença,

b - O parceiro de Sam morreu com uma faca no coração,

c - O parceiro de Sam morreu de morte morrida;

(37) a - O livro vai lhe custar dez reais só de raiva,

b- A equivale a B pela propriedade C.

Observe-se, porém, que a hierarquia temática determina a escolha, para as posições dos argumentos do predicador nas posições nucleares de "sujeito", "complemento" e na posição de complemento preposicionado. Em todos esses exemplos, os sintagmas preposicionados entram em uma estrutura de adjunção que escapam inteiramente ao princípio da hierarquia temática. Podemos, pois, formular o princípio geral que preside à estruturação argumental da diátese dos predicadores nas representações lexicais de um modo generalíssimo:

(38) a - A diátese lexical dos predicadores, em relação aos argumentos nucleares - sujeito/especificador e complemento - obedece a uma hierarquia temática.

(38) b - No Português, ${ }^{11}$ os papéis temáticos se ordenam hierarquicamente pelas propriedades que expressam:

CAUSAÇÃO > AFETAÇÃO > ESTATIVIDADE > DESTINAÇÃO ${ }^{12}$

2.3. Vimos, antes, que um evento pode ser descrito sob várias perspectivas e que tais perspectivas dependem, para manifestar-se sintaticamente, da existência de itens lexicais que expressem as 
diáteses correspondentes (como no caso de vender/comprar ou matar/morrer), dos recursos morfossintáticos disponíveis em uma dada língua (para a construção de passivas, antipassivas, aplicativas, causativas, etc.). Dependem, enfim, de processos componenciais e composicionais que, embora dependentes de propriedades dos itens lexicais, constituem estruturas de sentido que abrem diferentes possibilidades de instanciação/interpretação das estruturas sintáticas; fala-se, no caso em que se reordenam os argumentos, relativamente à hierarquia temática, de "promoções argumentais". ${ }^{13}$ Não iremos discutir esses processos, mas somente apontar, exemplificativamente, que hipóteses a teoria desenvolvida favorece.

Vale, antes, relembrar, em síntese, algumas condições temáticas sobre o fenômeno das "promoções argumentais" a que já nos referimos de passagem.

No caso das construções ergativas se excluem, na interpretação, um papel temático agentivo, mesmo implícito; $;^{14}$ o complemento "promovido" à posição de sujeito deve ser um argumento OBJETO AFETADO; ${ }^{15}$ estão, enfim, excluídos dessa construção verbos que selecionem outros papéis temáticos que não da macro-função CAUSA: a representação temática dos verbos que entram na alternância causativa/ergativa é, pois:

\section{$\mathrm{X}: \mathrm{V},\{$ CAUSA, OBJETO AFETADO $\}$}

Em Português, um grande número dessas construções admite (ou mesmo exige, sobretudo no Português Europeu) um clítico se, que se pode tratar como o reflexo morfológico da exclusão de um sujeito-temático Agente, ${ }^{16}$ possível nessa representação - uma operação envolvida na derivação, no léxico, das entradas ergativas a partir de causativas (BURZIO, 1981):

(39) a - O cristal partiu-se em mil pedaços,

b - Maria assustou-se com grito de Sam.

Nesse caso, nenhum problema se coloca para a Hierarquia Temática provisoriamente estabelecida. A seleção de Causa como "sujeito": 
(40) a - A queda dessa altura partiu o cristal em mil pedaços,

b - O grito de Sam assustou Maria,

se deriva naturalmente, e as construções de (39) são marcadas pela morfologia como excluindo o agentivo e reorientando a seleção argumental do Objeto Afetado como argumento nuclear "sujeito".

Dois conjuntos de construções, porém, necessitam uma análise mais cuidadosa. Primeiramente, mesmo no Português Europeu (ELISEU, 1984), há um conjunto de construções correlacionadas (causativas/ ergativas) que não admitem um clítico se:

(41) a - O governo aumentou os impostos exageradamente,

b - O excesso de trabalho envelheceu o professor,

(42) a - Os impostos (*se) aumentaram exageradamente,

b - O professor envelheceu( ${ }^{*}$-se),

Nesses casos, deve-se postular que, no processo de derivação lexical, não se trata de uma "ergativização", mas de uma "causativização", seguindo sugestão de WHITAKER-FRANCHI (1989) e ELISEU (1984). Em (43), uma construção agentivo-causativa, com um verbo habitualmente utilizado em sua forma intransitiva, aponta nessa direção:

(43) a - Os malandros correram da praça,

b - O policial correu os malandros da praça.

No Português coloquial do Brasil esse processo se vem estendendo, estranhamente, a inúmeros itens verbais:

(44) a - Eu vou almoçar primeiro as crianças, depois vejo isso,

b - Essa blusa me tá fazendo um calor danado,

c - É, esse sol está caducando o velho.

A hipótese é muito plausível. As diferenças estruturais entre as funções gramaticais de "sujeito" e "complemento" (do ponto de vista não somente sintático, mas semântico, como vimos) tornam a posição de sujeito gramatical o alvo imediato das operações que alteram a diátese 
verbal - passivação pessoal e impessoal, causativização, ergativização (BURZIO, 1981; ROBERTS, 1987), tanto de "detematização" quanto de "inserção". Este fato se expressa bem no Princípio do Argumento Externo de BORER e WEXLER (1987), relacionado a questões da aquisição:

(45) Salvo especificação em contrário, são externos todos os argumentos ou papéis- $\Theta$ que são apagados ou acrescentados por uma operação.

A razão é que a posição de sujeito não é uma posição estruturalmente visível à interpretação temática, como mostra o fato de poder não instanciar-se lexicalmente e de realizar-se mediante um expletivo, sem violar nem os princípios de projeção das estruturas relacionais temáticas. Se correta essa análise, os fatos exemplificados em (43) e (44) se derivam também naturalmente da Hierarquia Temática. A operação de causativização incorpora à diátese do predicador um papel temático da macro-função CAUSA, proeminente nessa hierarquia e o Paciente, ou, na ausência deste, um Resultativo na posição de complemento.

No Português do Brasil, entretanto, a contínua redução do sistema de clíticos e seu acentuado desuso, vem dispensando a "ergativização" da presença de um clítico se:

(46) a - O cristal partiu em mil pedaços,

b - A jangada espatifou no mar bravo,

c - Maria assustou com grito de Sam,

(agramaticais no Português Europeu, na avaliação de Eliseu). No dialeto mineiro, esse processo ainda se estende a quase todos os psico-verbos (CANÇADO, 1995):

(47) a - Sam não precisa preocupar tanto com isso,

b - Eu admiro muito com o que você está fazendo.

A hipótese de causativização está claramente excluída. Como explicar a alternância da Causa e do Objeto Afetado na posição de 
sujeito? Duas hipóteses nos vêm aqui à mente. A primeira consistiria em admitir uma "operação morfológica vazia" que determinasse a ergativização; essa operação assim formalizada reduziria o problema a uma simples questão de "construção marcada", como no caso de um clítico explícito. Na teoria que vimos desenvolvendo, porém, está o princípio metodológico de evitar-se, quanto possível, o custo ontológico das categorias vazias. Uma outra hipótese é a de que os papéis temáticos também se ordenam hierarquicamente em cada uma das macro-funções. Vamos explorar essa possibilidade.

Deve-se notar que a Hierarquia Temática, formulada em termos de macro-funções, esconde duas outras dimensões em sua linearidade. De fato, essas macro-funções são correlatas a papéis temáticos no "tier" da Locação e a seleção dos argumentos depende também de uma ordenação dos papéis específicos que nelas se incluem. Na macro-função CAUSA, Agente antecede sobre Causa e Instrumento:

(48) a - Sam quebrou o vaso de raiva,

b - * A raiva quebrou o vaso por/com/de Sam;

(49) a - Sam utilizou um martelo para quebrar a noz,

b - * O martelo utilizou para quebrar a noz;

e Causa antecede Instrumento: ${ }^{17}$

(50) a - A imersão no caldo inutilizou o produto com a composição que tem,

b - *A composição do caldo inutilizou o produto com a imersão nele.

No caso de verbos estativos o Experienciador antecede o Objetivo que antecede o Resultativo e outros papéis temáticos como Termo de Referência e Valor:

(51) a - João teme alguma traição,

b - O livro ficou o que nós desejávamos,

c - O prêmio vale o sacrifício que fizemos. 
Em qualquer caso, os papéis do "tier" da causação antecedem os papéis temáticos do "tier" da locação:

(52) a - A seta aponta o norte,

b - Os caminhos rodeiam o parque florestal,

c - Sam habita, faz anos, uma bela casa.

Esquematicamente, para os dados considerados, a hierarquia temática se constrói em uma esquema pluridimensional:

CAUSA $\Rightarrow$ OBJETO AFETADO $\Rightarrow \quad$ ESTATIVO

Agente Objeto Afetado Experienciador (estativo)

$\downarrow$

Causa

$\downarrow$

Instrumento
Experienciador (estativo)
$\downarrow$

Objetivo

$\downarrow$

Resultativo

Fonte

Movido

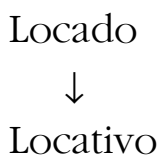

O que ocorre com as construções ergativas é que, excluído o Agente da posição de sujeito, e satisfeitas as condições restritivas acima, ficam disponíveis duas possibilidades de organização da estrutura argumental. A primeira, não ergativa, dada diretamente pela projeção da estrutura lexical (V: \{CAUSA, OBJETO AFETADO\}), obedecendo à hierarquia temática no eixo da macro-função CAUSA. A segunda, construída ergativamente, sem outras estipulações.

Para concluir, retomemos agora um exemplo anterior para mostrar os efeitos da componencialidade na instauração sintática de diferentes perspectivas discursivas que poderiam parecer uma 
ruptura da ordenação proposta na hierarquia temática. No texto sobre a teoria generalizada dos papéis temáticos, ao analisar a oração:

(54) O dr. Severo operou o nariz de Eduardo

representamos a proto-estrutura do evento-tipo nela descrito em um grafo relacional:

(55)

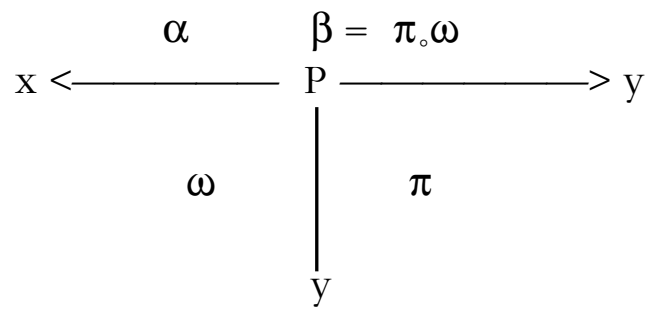

onde " $\alpha$ " designa a multi-relação que associa o evento (ou o que expressa o predicado complexo [operou o nariz de Eduardo]) a seu agentivo o médico; " $\omega$ ", a multi-relação entre o evento e seu paciente nariz; " $\pi$ " a multi-relação entre o objeto e seu possuidor Eduardo; " $\beta$ " a multi-relação entre o evento (ou o predicado nuclear complexo [ operou o nariz]) e seu benefactivo e que corresponde à composição das relações " $\pi$ " e " $\omega$ ".

O que é relevante para nosso tema é explicar, sob as condições do princípio da hierarquia temática, as instanciações:

(58) a) O Dr. Severo operou o nariz de Eduardo,

b) O nariz de Eduardo foi operado pelo Dr. Severo,

c) O Dr. Severo lhe operou o nariz (ao Eduardo),

d) Eduardo operou o nariz com o Dr. Severo.

As duas primeiras $(\mathrm{a}, \mathrm{b})$ se explicam diretamente pela projeção do predicador verbal em sua diátese plena e pela conversão passiva 
(v. nota 18). A oração (c) resulta, porém, de uma "re-interpretação" do evento em uma perspectiva em que o argumento Eduardo se toma como determinado pela relação semântica composicional das relações $\pi$ e $\omega=\pi$. $\omega=\beta$ que o associa a um papel temático "Beneficiário". No co-texto oracional, ainda, pode-se atribuir ao beneficiário (pragmaticamente) a iniciativa no processo, como em (58-c), ou:

(59) Eduardo se fez operar o nariz pelo dr. Severo,

Há mais: o beneficiário, como vimos, pode associar-se em muitos contextos a traços de afetação e se comporta como um Objeto Afetado. Por exemplo, pode atribuir a essa qualidade temática uma expansão mediante um adverbial ou um predicado secundário do complemento, como em:

(60) O barbeiro cortou o(s) cabelo(s) desse garoto muito rente/curto.

No Português do Brasil, pelo menos no dialeto do interior paulista, uma construção passiva é possível e representa justamente essa interpretação:

(61) Esse garoto foi cortado o cabelo muito rente.

indiscutivelmente mais apropriada se na opinião do falante ou na opinião que o falante atribui ao próprio garoto esse não era o corte desejado e isso "afeta" o garoto. ${ }^{18}$

O que é importante destacar é que esses condicionantes de natureza semântica não podem em princípio ser tratados como propriedades lexicais (nem mesmo mediante regras de redundância no léxico): resultam da construção componencial e composicional do sentido em esquemas relacionais bem determinados, da qual se derivam os traços semânticos relevantes de agentividade ou afetação do argumento "promovido" a sujeito gramatical. 


\section{NOTAS}

${ }^{1}$ Diferentes propostas e uma vasta argumentação a favor de uma hierarquia temática podem-se ver em FILLMORE, 1968; JACKENDOFF, 1972, 1976, 1983, 1990; CARTER, 1976; MARANTZ, 1984; FOLEY e VALIN, 1984; CARRIER-DUNCAN, 1985; GRIMSHAW, 1987, 1990; BRESNAN e KANERVA, 1989; HUDSON, 1992. Uma referência à hierarquia teórica em explicações sintáticas também se tem feito na literatura gerativista; por exemplo, GIORGI (1984).

${ }^{2}$ Essa é a intuição que se expressa no princípio de visibilidade tal como sugerido inicialmente por Aoun e formulado por CHOMSKY, 1986, como propriedade de "cadeias argumentais". Reformulando o antigo "Filtro de Caso que exigia que todo NP foneticamente realizado recebesse um Caso morfológico ou abstrato (ver ROUVERET e VERGNAUD, 1980; VERGNAUD, 1982), CHOMSKY (1981) assume que um elemento é visível para a "marcação- $\Theta$ " (e, pois, para a interpretação) somente se lhe é atribuído um Caso, ou seja, se está em uma posição à qual é atribuído um Caso. (v. "Predicação", 1.3).

${ }^{3}$ Obviamente, há sempre interesse teórico em reduzir esses vários modos de atribuição de caso a um procedimento uniforme no sistema formal explicativo. É o esforço da teoria de Princípios e Parâmetros Caso a Concordância, ou do minimalismo via movimentos para "checagem" dos traços morfológicos, entre eles os de Caso.

${ }^{4} \mathrm{Na}$ elaboração da teoria e das representações abstratas sobre a qual operamos, devem-se respeitar meta-critérios de economia, simplicidade/não redundância, elegância. Não estamos, porém, assumindo que tais propriedades são inerentes à forma gramatical das línguas naturais (propriedades da linguagem-objeto). Mas deve-se considerar com respeito a decisão contrária de CHOMSKY (1995-b).

${ }^{5}$ Começar entra em construções ergativas e causativas, pelo que sua diátese contém uma macro-função CAUSA e não um papel temático Causa ou Agente:

$$
\begin{aligned}
& \text { a - As encrencas começaram com a renúncia de João ao cargo, } \\
& \text { b - A renúncia de João ao cargo começou as encrencas, } \\
& \text { c - João, com sua renúncia, começou deliberadamente as encrencas. }
\end{aligned}
$$

A distinção entre o Locativo - lugar/tempo do evento como propriedade da diátese de um predicador verbal e o Locativo "adverbial" expresso por uma adjunção como propriedade da diátese da preposição, fica evidente no contraste entre (b) e (c) dos exemplos:

(ii) a - Sam começou as provas às dez horas em ponto neste ano,

b - Neste ano, Sam começou as provas às dez horas,

c - *Às dez horas, Sam começou as aulas neste ano. 
(iii) a - Toda rua começa em uma praça na minha cidade,

b - Na minha cidade, toda rua começa em uma praça,

c - *Em uma praça, toda rua começa em minha cidade.

${ }^{6}$ Quanto à exclusão da agentividade lembre-se a agramaticalidade já observada de:

(i) a - Maria assassinou o companheiro,

* O companheiro assassinou.

Que a agentividade não pode sequer estar implícita se vê em:

(ii) a - O vaso quebrou por descuido,

b - * O vaso quebrou por Sam / * O vaso quebrou voluntariamente,

ou ainda em (iii), em que a agramaticalidade decorre da impossibilidade de controle por um agentivo implícito (ao contrário da passiva)

(iii) a - [O vaso foi quebrado/quebrou-se o vaso] para tirar as nozes de dentro, d - * O vaso quebrou para tirar as nozes de dentro.

7 Apenas como indicação, obtivemos aproximadamente, sobre uma amostra de 500 verbos, a seguinte distribuição de percentuais: verbos de "ação-processo": $420=84 \%$; "de ação" (atividade): 50 = 10\%; "de processo": 15 = 3\%; "de estado": $15=3 \%$. Estes dados colocam sob suspeita a explicação discursiva (baseada em "fluxo de informação") da proeminência do agentivo-sujeito em análises quantitativas da ocorrências dessa realização. Não poderia ser de outra forma, dada a enorme predominância dos verbos de "ação": 94\%.

${ }^{8}$ Outra vez deixo de considerar o papel temático habitualmente chamado de Forças. Na verdade, esse papel temático se substitui ao Agente (quando o verbo não é tipicamente agentivo) sempre que o elemento tomado como argumento sujeito possui um "movimento" ou "ação" próprios ou considerado independentemente do Agente que o põe em movimento ou em ação:

(i) a - Os agricultores derrubam as folhas com o vento (do compressor),

b - O vento do compressor derruba as folhas;

(ii) a - João está puxando água com o motor da bomba, b - O motor da bomba está puxando a água;

(iii) a - Os bombeiros levaram o elefante num caminhão, c - O caminhão dos bombeiros levou o elefante.

${ }^{9}$ A caracterização do Objetivo tem sido feita mais negativamente: um elemento que especifica o processo mas não é modificado por ele, nem resulta dele. Um outro possível fenômeno (além de casos de promoção argumental já examinados) 
que pode justificar a distinção do Objetivo de outros papéis temáticos é o de um contraste na substituição dos predicadores, por um predicador complexo formado de um verbo suporte e um nome deverbal. Fazer/ter ocorrem no caso de o complemento ser ESTATIVO:

(i) Sam matou o parceiro $>$ causou/* fez/* tem a morte do parceiro,

(ii) a - Sam redigiu a carta $>*$ causou/fez a redação da carta,

b - Sam comprou a casa $>*$ causou/fez a compra da casa,

c - Sam conhece a teoria $>$ * causou/tem conhecimento da teoria,

d - Sam usou a faca $>$ * causou/fez uso da faca,

f - O livro custou dez reais $>$ * causou/teve um custo de dez reais.

${ }^{10}$ Não encontramos (e provavelmente não se encontram nas línguas naturais) argumentos da macro-função DESTINAÇÃO em posição de "sujeito". Lembre-se de que não identificamos Beneficiário a Meta (no "tier" da locação) e que a análise dos casos em que o Beneficiário ocupa a posição de sujeito depende menos dos traços específicos com que se costuma definir esse papel temático e mais dos traços de agentividade e de afetação com que podem ser interpretados.

${ }^{11}$ Não dispomos de dados satisfatórios que nos permitam estender a análise realizada e a hierarquia temática definida a outras línguas. Vale sempre, porém, o princípio geral da hierarquia temática.

${ }^{12}$ Não se pode deixar de especular sobre a "iconicidade" dessa ordenação: vai da "Origem" (CAUSA/FONTE) ao "Termo" (DESTINAÇÃO/META) do processo, tomando como elementos nucleares os objetos que "transitam" nessa linha do espaço-tempo.

${ }^{13}$ O termo é evidentemente descritivo. DOWTY (1991) considera o fenômeno da promoção argumental o domínio descritivo sobre o qual melhor se pode encontrar argumentos para a hipótese de relevância gramatical das relações temáticas (mais que as generalizações descritivas sobre a organização da representação lexical). Ver, ainda, RAPPAPORT e LEVIN (1988), JACKENDOFF, 1990; LEVIN, 1993; LEVIN e RAPPAPORT-HOVAV, 1995.

${ }^{14}$ Ver PIMENTA-BUENO, 1979; BURZIO, 1981; ELISEU, 1984; WHITAKERFRANCHI, 1989.

${ }^{15}$ Ver WHITAKER-FRANCHI, 1989; LEVIN, 1989; ZUBIZARRETA, 1992; CANÇADO, 1995.

${ }^{16}$ Isso se estende a todos os processos morfossintáticos que levam a um rearranjo da estrutura argumental. Devem ser tratados como resultantes do sentido associado a esses processos. Assim, no caso da estrutura argumental da construção passiva 
e das restrições a sua aceitabilidade. No português, a morfologia do particípio passado expressa no léxico uma mudança categorial (do verbo à sua forma adjetiva) e uma exclusão do Agente de sua posição proeminente na hierarquia temática e, pois, de sua posição sintática nuclear:

$$
\mathrm{N}_{1} \mathrm{~V} \mathrm{~N}_{2} \longrightarrow \text { [ Ser }\left[\left[\mathrm{N}_{2} \mathrm{Vdo}\right] \text { por } \mathrm{N}_{1}\right]
$$

cuja interpretação implica causação direta do processo por $\mathrm{N}_{1}$, expressa no caso do Agente pela noção de controle.

${ }^{17}$ As restrições são maiores, aliás, à promoção da Causa e mais ainda à promoção do Instrumento à posição de sujeito. Ver, por exemplo, GIVÓN, 1984.

${ }^{18}$ Essas passivas com uma espécie de incorporação do objeto são aliás mais freqüentes do que parece à primeira vista. Outros exemplos (ILARI e FRANCHI, 1994):

(i) Você já tá tomado banho?

(ii) Ele é para ser tomado conta, hein?

(iii) Nessa hora, eu já tava tomado umas.

(iv) Essa camisa que está sendo pregada botão, você vai levar?

(v) Essas moças o que querem é ser passada a mão na bunda.

Em todas essas orações, o predicado complexo formado pelo núcleo verbal e seu objeto atribuem composicionalmente ao sujeito derivado um papel temático adicional de objeto afetado. 